\title{
The Sulphur Directive and Stakeholders of Estonia's Maritime Sector
}

\author{
Eva Branten ${ }^{1}$, Alari Purju ${ }^{2},{ }^{1,2}$ Tallinn University of Technology
}

\begin{abstract}
The paper examines Estonia's maritime sector from the point of view of its stakeholders and their strategic choices regarding several critical issues. Business activities of maritime sector are dependent on public services and regulations on safety, security related services and regulations, environmental conditions related issues, and the sulphur emission regulation which will be introduced from 2015 , as the most recent example. One impact of this dependence is that a big number of different stakeholders are involved and would like to see their values and preferences are brought into governance process. The paper provides a structured overview of these stakeholders and their position in governance issues.
\end{abstract}

Keywords - Estonian maritime cluster, environmental policy, public governance, stakeholders.

\section{INTRODUCTION}

The object of this paper is the position of different stakeholders of maritime sector. The Estonian maritime business sector has three large components: infrastructure (ports), operating services (shipping and cargo treatment) and shipbuilding and repair. The ports provide first of all infrastructure for other activities. Shipping companies operate ships and their networks depend on their customers. They deal with passengers or cargo, or both. The activities of cargo and service companies are based on networks because their main business is to serve owners of traded products by transporting these products from one geographical location to another and providing all necessary services for it. The shipbuilding and repair companies produce ships and provide different kinds of repair services to the ship owners. In particular, the ports and passenger ships provide services related to retail and wholesale trade, catering and entertainment, therefore they are closely linked to different types of tourism. The ships also need such services as repair, bunkering and pilot service. Hence, this interrelated maritime sector in aggregate creates quite a sizeable amount of Estonia's GDP - up to $10 \%$ [1], [2, pp. 3-4].

The maritime sector activities are using the Baltic Sea which is a natural resource and environment for the countries on the coast of it and also part of a wider ecosystem. The maritime sector companies operating in the area have to take into account the special requirements set by the natural conditions of the Baltic Sea. The sea has high emotional value for the inhabitants of those countries. There is a well-known historical heritage related to the development of nations in the area. That makes developments related to the use of the sea very sensitive and creates a good basis for public interest. Due to the important role played by the maritime sector in
Estonia's economy and the accompanied controversial externalities to its support, there have been calls for institutional arrangements that take into account the public interest [3], [4], [5], [6].

The legal framework for vessel traffic has been tightening, and the sulphur emission regulation will be introduced from 2015, as the most recent example ${ }^{1}$. The shipping companies have in principle three ways of adjustment to the new regulation:

1) purification of emission with scrubbers;

2) using better and more expensive fuel;

3) designing LNG using engines.

Current fleets need to be reviewed and renewed, which means getting rid of old tonnage and making sure that the rest meets the new demands regarding environment and fuel efficiency. These requirements introduced by the sulphur directive have been an activator of stakeholders.

The aim of the paper is to examine the strategic choices of Estonia's maritime sector. The problem is related to a big number of different stakeholders who are involved and would like to see their preferences are brought into governance process. At the same time, their reaction patterns depend on their position as a stakeholder. The paper applies the typology of stakeholders and makes suggestions for the governance of the maritime sector. The paper is based on the results of the EU Interreg project "Smart Competitiveness for the Central Baltic Region".

${ }^{1}$ Shipping is regulated to a large extent by global provisions accepted within the framework of the International Maritime Organization (IMO). IMO is the United Nations specialized agency with responsibility for the safety and security of shipping and the prevention of marine pollution by ships. The International Convention for the Prevention of Pollution from Ships (MARPOL) is the main international convention concerning prevention of pollution of the marine environment by ships from operational or accidental causes [7]. MARPOL (Annex VI) introduces conditions for $\mathrm{SO}_{\mathrm{x}}$ in the Baltic Sea. The sulphur content of any fuel oil used on board ships within the Baltic Sea, which is a $\mathrm{SO}_{\mathrm{x}}$ Emission Control Area, currently set at the level of $1.00 \% \mathrm{~m} / \mathrm{m}$ (from 1 July 2010), shall not exceed $0.10 \% \mathrm{~m} / \mathrm{m}$ from 1 January 2015. Global sulphur limits (including EU countries not in the SECA) are $3.5 \%$ from 2012 and $0.5 \%$ from 2020, if feasible otherwise from 2025 [7]. In addition to the SECA areas, from 2015 a standard of $0.1 \%$ sulphur content in marine fuels will also stand for the 12-mile zone along all coasts in the European Union. On 29 October 2012, the Council of the European Union adopted the Directive 2012/33/EU which sets requirements pursuant to MARPOL Annex VI. The directive was approved by the European Parliament on 8 November 2012. The EU members shall bring their laws on marine fuels into accordance with the sulphur directive by 18 June 2014. Since the directive requires large-scale fast amendments to ships, it also allows to a certain extent State support. Member States may provide support to operators in accordance with the applicable State aid rules [8]. 


\section{METHOD: QUALITATIVE TYPOLOGY OF STAKEHOLDERS AND ITS APPLICATION}

The stakeholders' impact and its dynamics are derived from a semi-structured interview with key stakeholders. Reaction to the requirements of the sulphur directive has been considered as an activator of stakeholders.

In very general terms a stakeholder is defined as "any group or individual who can affect or is affected by the achievement of the organization's objectives" [9]. Mitchell et al. have developed a classification based on three attributes: legitimacy, power and urgency [10].

Fig. 1 describes the possibilities of involvement in a company's decision making.

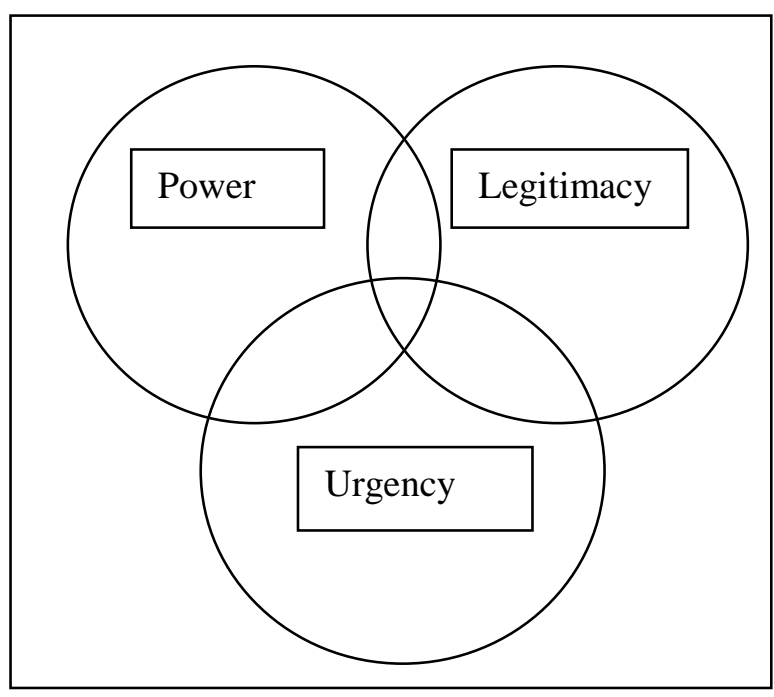

Fig. 1. Qualitative classes of stakeholders [10].

The legitimacy is related to the presence of a legal, moral or presumed claim [11]. Power is possessed by stakeholders who are in a position to influence the company's decisions. The urgency is related to a possibility or to a need to demand immediate attention from managers [10]. Being a stakeholder requires either a legitimate claim, an urgent problem or crises which should be solved, or more or less power to influence the company's decisions. The stakeholders could have one, two or three of these attributes describing the possibilities of involvement in company's decision making [10].

The seven types of stakeholders examined are the following: three-possessing only one attribute; three-possessing two attributes; and one-possessing all three attributes. According to the concept in [10], the latent stakeholders hold only one of the attributes - legitimacy, power or urgency [10]. Actors with legitimate claims but without power or demand that require immediate actions are discretionary stakeholders for the company [10]. The position of groups with power but without legitimate claim and urgent demands depends on the extent they are willing or able to use their power (dormant stakeholders). They are stakeholders in reserve and could be activated by the actual use of power or by a threat to use it [11]. Groups with urgent claims but lacking power and legitimacy are irksome but not dangerous (demanding stakeholders) [10].

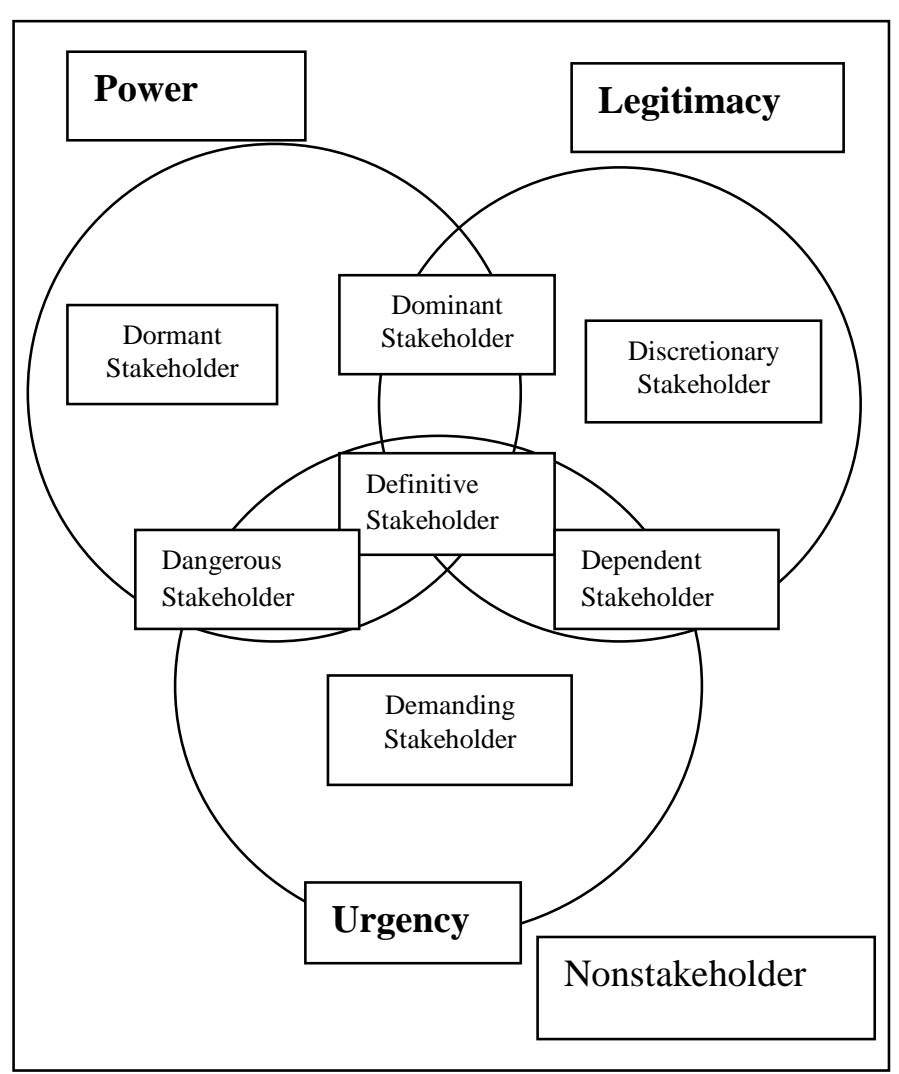

Fig. 2. Stakeholders' typology: Qualitative classes of stakeholders. One, two or three attributes present [10].

The expectant stakeholders are those who possess two of the three attributes and they are in a more active relationship with the company [11]. Groups and organizations with legitimacy and power like government agencies have to be taken into account and for that reason they are dominant stakeholders [11]. The stakeholders which are legitimate and with urgency claim, but without power to enforce it, could use media attention and get attraction of powerful stakeholders. Building alliances and appealing to the values of managers are their relevant strategies [11]. They are dependent stakeholders. There is also a possibility that the stakeholders have power and possess urgency, but lack legitimacy. This group of stakeholders will support their interests through the use of force. They are dangerous for companies' stakeholders [11].

The definitive stakeholders are those who possess power, legitimacy and urgency [10]. Definitive stakeholders are those groups or individuals whose demands managers of companies should take into account. Fig. 2 illustrates the seven types of stakeholders examined: three - possessing only one attribute; three-possessing two attributes; and one-possessing all three attributes. These groups include shareholders, employees and customers, but also government agencies if the latter are in a position to use their power to solve certain critical problems.

The position of different groups of stakeholders is dynamic [10]. Situation, changes in political system and also regulations could change the nature of the claim of one or another group of stakeholders. The stakeholders themselves are active in improving their position. The stakeholders' 
structure is influenced by the area of activities. One example is the analysis of typology of stakeholders of Norwegian fisheries [11].

\section{RESUlts: THE POSITION OF THE STAKEHOLDERS OF THE MARITIME SECTOR}

The typology of stakeholders of Estonia's maritime sector has been worked out by the authors of the current paper.

The definitive stakeholders in Estonia's maritime sector are government agencies for the reason that they have power and legitimacy to act and also urgency, as related to the need to introduce respective legislation which is foreseen by international commitments. Especially for the Ministry of Economic Affairs and Communications the impact of possible decline in turnover and revenue due to the impact of the new regulation in the sector will be a major concern. The shipping companies are definitive stakeholders in relation to other partners in the maritime sector because their decisions on shipping lines are crucially framing the flow of traded goods. The ports and cargo handling companies depend more on the decisions of shipping lines than the other way round. The routes of ocean lines are especially important in framing the global cargo flow. The ports visited by these shipping lines are the destinations of reframing transport flow into smaller lines, and cargo handling companies adjust wishes of their clients on ports of arrival of goods to availability of options provided by the shipping lines.

Ports, cargo handling and shipbuilding companies are all in different ways dependent on the new requirements. Ports have to develop new infrastructure to serve waste treatment. Cargo handling companies have to adjust their services to new conditions taking into account also additional costs. Shipbuilding companies should develop new products taking into account new technical conditions. All these industries have legitimacy of claims because the new regulations have quite a substantial impact on their business activities. They all are legitimate stakeholders with urgency claim, but without power to enforce it. Building of alliances and appealing to the values of decision makers are their relevant strategies and for that reason they are dependent stakeholders. At the same time they have certain limited tools to have influence on certain decisions. State-owned ports are an important source of tax revenue and they have certain power in economic decisions which have impact on other companies (sale or rent of capacity for terminals). Cargo handling and shipbuilding companies also create tax revenue, provide employment and demand for services of other industries. Local governments have impact on certain concrete decisions like sale or rent of additional land for ports. At the same time, they are dependent on tax revenues (income tax connected to inhabitants of local government and land tax connected to its territory) created by these business activities. Associations of Maritime Sector related activities are urgency and legitimacy for actions because they represent companies which are very directly influenced by the new regulation. They have access to government agencies but their direct power is limited and they can act as a lobby group intermediating information between the government agencies and companies. The environmental groups have urgency and legitimacy for actions but their impact is even lower and they can make their voice heard through local governments or state agencies.

TABLE I

MARINE SECTOR STAKEHOLDERS AND THEIR IMPACT [12]

\begin{tabular}{|c|c|c|c|}
\hline Stakeholders & Power & Legitimacy & Urgency \\
\hline \multicolumn{4}{|l|}{ Definitive } \\
\hline $\begin{array}{l}\text { Ministry of } \\
\text { Environment }\end{array}$ & High & High & High \\
\hline $\begin{array}{l}\text { Ministry of Economic } \\
\text { Affairs and }\end{array}$ & High & High & High \\
\hline $\begin{array}{l}\text { Communications } \\
\text { Shipping companies }\end{array}$ & High & High & High \\
\hline \multicolumn{4}{|l|}{ Expectant } \\
\hline Ports & Medium & High & High \\
\hline $\begin{array}{l}\text { Cargo handling } \\
\text { companies }\end{array}$ & Medium & High & High \\
\hline $\begin{array}{l}\text { Associations of } \\
\text { maritime industry }\end{array}$ & Medium & High & High \\
\hline Local governments & Medium & High & High \\
\hline (concerned) & Low & High & High \\
\hline $\begin{array}{l}\text { Shipbuilding } \\
\text { Environmental groups }\end{array}$ & Low & High & High \\
\hline \multicolumn{4}{|l|}{ Latent } \\
\hline Media & High & Medium & Medium \\
\hline Banks & High & Low & Low \\
\hline Trade unions & Medium & High & Medium \\
\hline Academic institutions & Medium & High & Medium \\
\hline Tourism industry & Medium & Low & Low \\
\hline Local communities & Low & High & Medium \\
\hline Citizens & Low & High & Low \\
\hline Future generations & Low & High & Low \\
\hline
\end{tabular}

In Estonia's maritime sector trade unions, academic institutions, local communities and citizens are actors with legitimate claims but without power or demand that require immediate actions and for those reasons they are stakeholders at their discretion. Trade unions have only medium level power because in Estonia coverage of trade unions is low only around $10 \%$ of employees belong to trade unions [13], nevertheless the Independent Trade Union of Estonian Seamen is relatively active and has some influence. Citizens have the claim of environmental conditions claim, including conditions of sea, but their direct impact on solutions is limited and their demands can be considered if they are presented by intermediating bodies. Academic institutions have legitimacy and obligation to examine environmental conditions and develop technology for industries, but their impact depends on access to political decision making and urgency for particular businesses. In Estonia, the academic lobby in political decision making and also in industry is not very strong. In the latter case the reason is that even Estonian companies use international expertise in product development first of all. Estonia's small academic community could specialize in certain niche areas of product development but presently it is not clear for producers in which specialized areas the strengths lie.

Media belong to the subtype of stakeholders with relative power (even government agencies should be influenced, 
especially in sensitive areas like environmental conditions of sea). The faith of maritime industry is not an extremely urgent topic for media and as there could only be medium to long term processes dealing with critical issues and providing solutions, the media are not patient enough to go into details. That makes media a dormant stakeholder, that is, they are willing or able to use their power to certain extent. Banks also belong to this group but their claims are even less urgent and very project based. They are stakeholders in reserve and could be activated by the actual use of power or by the threat to use it. Tourism industry is dependent on certain services provided by the maritime sector but for them also substituting products are available. Future generations naturally have legitimacy for reliable environmental conditions but especially in the countries with relatively pragmatic short and medium term approach to business activities and the related use of natural resources the urgency and power are limited in taking their interests into account.

\section{DISCUSSION AND CONCLUSION}

The object of this paper is the position of different stakeholders of Estonia's maritime sector. The requirements introduced by the sulphur directive have been an activator of stakeholders. On basis of the analysis it is possible to conclude that the urgency of stakeholders' reactions depends on the impact of new environmental regulations on their business activities and extra costs caused by these regulations. The power of stakeholders determines the influence they can have on the decisions and solutions of other stakeholders. The legitimacy of actions concerns legal, moral and presumed claims on the issues. The analysis of structure of stakeholders and their position in a particular country supports the design of cooperation strategies which take into account economic and business features of these countries. This typology based approach makes it possible to produce realistic suggestions for a particular country how to further develop its maritime sector and what could be the ways to create national and regional clusters. The analysis of roles of stakeholders suggests that there should be increasing cooperation between the maritime associations and the political actors. It is very important to organize targeted problem solving networking events with participation of representatives from maritime associations, government agencies, research institutions and companies.

\section{REFERENCES}

[1] Purju, A., Dedegkajeva, I., Soosaar, R., "The Role and Share of Transit in Estonian Economy," Studies in Industrial Engineering and Management. Lappeenranta University of Technology, 2003, pp. 285-293.

[2] Portsmuth, R., Hunt, T., Terk, E., et al., "Estonian Maritime Cluster," Proceedings of Estonian Maritime Academy, no. 13, 2012.

[3] Blue Growth. 2012. Communication from the Commission: "Blue Growth," Opportunities for Marine and Maritime Sustainable Growth. COM/2012/0494/Final.

[4] HELCOM. 2007, „Baltic Sea Action Plan,“ [Online]. [Accessed 19.06.2013.]. Available: http://helcom.fi/Documents/Baltic\%20sea $\% 20$ action\%20plan/BSAP_Final.pdf.

[5] Schinas, O., Stefanakos, C. N., "Cost Assessment of Environmental Regulation and Options for Marine Operators," Transportation Research Part C, 2012, vol. 25, pp. 81-99. http://dx.doi.org/10.1016/j.trc.2012.05.002

[6] Surís-Regueiro, J. C., Garza-Gil, M. D., Varela-Lafuente, M. M., "Marine Economy: A Proposal for Its Definition in the European Union," Marine Policy, 2013, 42, pp. 111-124.

http://dx.doi.org/10.1016/j.marpol.2013.02.010

[7] IMO International Maritime Organization, "International Convention for the Prevention of Pollution from Ships," [Online]. [Accessed 19.06.2013.]. Available: http://www.imo.org/About/Conventions/ListOfConventions/Pages/ International-Convention-for-the-Prevention-of-Pollution-from-Ships(MARPOL).aspx.

[8] EUR-Lex, "Directive 2012/33/EU of the European Parliament and of the Council of 21 November 2012 amending Council Directive 1999/32/EC as Regards the Sulphur Content of Marine Fuels," Official Journal of European Union, 27.11.2012.

[9] Freeman, R., Strategic Management: A Stakeholder Approach. Boston: Bitman, 1984.

[10] Mitchell, R. K., Agle, B. R., Wood, D. J., "Toward a Theory of Stakeholder Identification and Salience: Defining the Principle of Who and What Really Counts," The Academy of Management Review, 1997, vol. 22 , no. 4 , pp. 853-886.

[11] Mikalsen, K. H., Jentoft, S., "From User-Groups to Stakeholders? The Public Interest in Fisheries Management," Marine Policy, 2001, vol. 25, no. 4, pp. 281-292. http://dx.doi.org/10.1016/S0308-597X(01)00015-X

[12] SmartComp Research Report no. 2. Maritime companies and their business networks in the Central Baltic region. 2013.

[13] Viilmann, N., Soosaar, O., "Estonia's Labour Market Review," Bank of Estonia, 1, 2012.

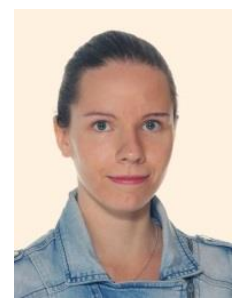

Eva Branten graduated from the School of Economics and Business Administration of Tallinn University of Technology, in 2012. She is a Project Research Associate with the Department of Logistics and Transport of Tallinn University of Technology.

E-mail address: evabranten@gmail.com

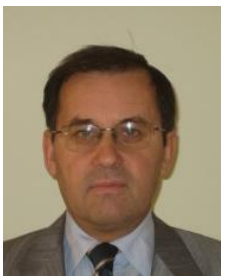

Alari Purju is Head of Department of Logistics and Transport of Tallinn University of Technology (TUT) and a Visiting Professor. He has been the Dean of the Faculty of Economics and Business Administration of TUT and an Advisor to the Minister of Economic Affairs of Estonia as well as a Consultant to the World Bank (The Commission for Growth and Development), the OECD and the EU Commission.

E-mail address: alari.purju@ttu.ee 